\title{
Penggunaan Operkulum dalam Penentuan Umur pada Rhinoclavis sinensis Gmelin 1791 (Gastropoda: Cerithiidae)
}

\author{
The Use of Operculum in Age Determination of Rhinoclavis sinensis Gmelin 1791 \\ (Gastropoda: Cerithiidae)
}

\author{
Felicia Zahida $^{1 *}$ dan Jusup Subagja ${ }^{2}$ \\ ${ }^{I}$ Fakultas Teknobiologi, Universitas Atma Jaya Yogyakarta \\ ${ }^{2}$ Fakultas Biologi, Universitas Gadjah Mada \\ Jl. Babarsari 44, Yogyakarta 55281 \\ E-mail:feliciazda@mail.uajy.ac.id *Penulis untuk korespondensi
}

\begin{abstract}
Age determination of the sample specimen is very important for population dynamic research of $R$. sinensis (Gastropoda : Cerithiidae). Operculum is a "hard" part stick on the dorsal portion of the foot of gastropods. Operculum appeared on the day of the snails are born and have their own specific shape, size, and materials composition. The aim of this research was to describe the use of operculum in age determination of $R$. sinensis. The method used in this research was: the operculums were soaked into saturated sodium hydroxide, washed and mounted them in Canada balsam, and observed using binocular microscope. Regression analysis was used to find the relationship between length of operculum to length of shell, and number of adventicious layers of operculum to length of shell. The research resulted that the length of operculum was comparable with the shell length, with the regression line of $Y=0.113 X+1.898\left(R^{2}=0.857\right)$. The growth of adventitious' layers of the operculum coincided with the growth of the shell that in the second year, the growth of adventitious layers was two layers a year. At the age of three and four, the growth was one layer a year. During the fifth, sixth and seventh years, the growth was only a layer within three years. The regression line was $Y=0.168 X\left(R^{2}=0.872\right)$.
\end{abstract}

Key words: operculum, Rhinoclavis sinensis, age determination, Gastropoda, Cerithiidae

\begin{abstract}
Abstrak
Penentuan umur spesimen dalam sampel amat penting bagi penelitian dinamika populasi dari Rhinoclavis sinensis (Gastropoda : Cerithiidae). Operkulum merupakan bagian "keras" yang melekat pada bagian dorsal kaki perut gastropoda. Operkulum ada sejak siput laut lahir dengan bentuk, ukuran dan bahan khas jenis. Tujuan penelitian ini adalah mengungkapkan penggunaan operkulum dalam penentuan umur $R$. sinensis. Metode yang digunakan adalah dengan perendaman dalam $\mathrm{NaOH}$ jenuh, dibilas dan selanjutnya ditanam dengan Canada balsam, dan diamati menggunakan mikroskop binokuler. Analisis regresi dipergunakan untuk mencari hubungan antara panjang operkulum dan panjang cangkang, serta jumlah lapisan operkulum dan panjang cangkang. Hasil penelitian menunjukkan bahwa panjang operkulum sebanding dengan panjang cangkang, dengan persamaan garis regresi $Y=0,113 X+1,898$ $\left(\mathbf{R}^{2}=0,857\right)$. Pertumbuhan lapisan operkulum berlangsung seiring dengan pertumbuhan cangkangnya, yaitu: hingga usia dua tahun, dua lapis operkulum per tahun. Umur tiga dan empat tahun tumbuh selapis per tahun, selanjutnya pada umur lima, enam, tujuh tahun, selapis dalam tiga tahun. Persamaan garis regresi yang terbentuk $Y=0,168 X\left(R^{2}=0,872\right)$.
\end{abstract}

Kata kunci: operkulum, Rhinoclavis sinensis, penentuan umur, Gastropoda, Cerithiidae

Diterima: 23 Agustus 2010, disetujui: 29 Oktober 2010

\section{Pendahuluan}

Penggunaan operkulum sebagai penentu
umur sudah dikenal dalam publikasi international, tetapi penelitian mengenai operkulum di Indonesia masih sangat terbatas. Uraian mengenai operkulum beserta jenisjenisnya dijelaskan cukup lengkap oleh Monfils 
(2000). Namun monograf yang disusun oleh Houbrick (1978), ternyata belum dapat memberikan informasi umur. Selain itu menurut Richardson et al., (2005a) metode penentuan umur pada jenis tertentu, belum tentu dapat diterapkan pada jenis yang lain, atau bila dapat diterapkan pada jenis tersebut, kadangkala hanya berlaku pada kelas umur tertentu.

Operkulum dikatakan berbahan tanduk (corneus atau horny), jika tidak terkalsifikasi, dan jika sangat terkalsifikasi disebut calcareous. Inti operkulum terbentuk pada saat embrionik. Dalam pertumbuhannya kemudian bercabang menjadi dua pola yaitu spiral atau konsentris (memiliki pusat yang sama). Operkulum yang tumbuh spiral dibagi lagi menjadi multispiral (atau polygorous) pada jenis-jenis yang berulir banyak, atau paucispiral (atau oligogyrous) pada jenis-jenis yang berulir sedikit (Monfils, 2000).

Conchiolin didepositkan hanya pada bagian sisi permukaannya yang paucispiral, kemudian seiring dengan pertumbuhan operkulum secara bertahap tumbuh berotasi dengan berpusat pada lempeng operkulum. Pada $R$. sinensis sisi permukaan ini terlihat beraluralur, sedangkan bagian sisi dalam operkulum yang berlekatan dengan kaki perut menunjukkan lapisan-lapisan konsentris, bagian sisi perlekatan ini, selama pertumbuhannya tidak mengalami rotasi.

Penentuan umur berada pada tataran populasi yang memiliki hari lahir yang sama yang disebut kohort. Umur dimulai dari hari lahirnya, yaitu hari menetasnya larva dari telur. Dalam penentuan umur siput ini digunakan operkulum yang diharapkan memiliki sifat yang serupa dengan sisik atau otolit (tulang telinga) pada ikan, yaitu stabil sepanjang hidup, pertumbuhan sebanding dengan pertumbuhan panjang cangkang, serta penambahan lapisan operkulum setiap tahun. Pada Gastropoda penentuan umur selain dilakukan dengan operkulum (Richardson et al., 2005a) bisa juga dilakukan dengan menggunakan striae/lapisan bergerigi yang terdapat pada cangkang (Richardson et al., 2005a, pada gastropoda dan Ramon et al., 1995; Aldridge, 1999; Gaspar et al., 2004, pada bivalvia), atau striae pada permukaan operkulum (Kideys, 1996) atau menggunakan statolit (Richardson et al., 2005a,b).
Penelitian ini mencoba mengungkapkan penggunaan operkulum sebagai penentu umur, baik dari panjang operkulum maupun dari jumlah lapisan adventisiusnya. Hasil penentuan umur ini nantinya digunakan sebagai pembanding hasil penentuan umur menggunakan nilai kurvatur pertumbuhan data frekuensi panjang cangkang.

\section{Metode Penelitian}

Sejumlah 165 sampel siput dikoleksi dan diawetkan dalam alkohol $70 \%$ pada bulan April 2008 di Pantai Krakal Yogyakarta. Sampel diukur panjang cangkang serta panjang operkulumnya menggunakan Vernier Caliper dengan ketelitian $0,1 \mathrm{~mm}$ dan dicari kecepatan pertumbuhannya dengan von Bertalanffy growth formula (VBGF), dan didapatkan nilai K: kurvatur kecepatan pertumbuhan. Kemudian satu persatu operkulum dipisahkan dari otot kakinya secara hati-hati menggunakan scalpel. Proses ini dilakukan dengan memutuskan ikatan dagingcangkangnya pada kolumela.

Operkulum direndam satu jam dalam $\mathrm{NaOH}$ jenuh sehingga bersih dari sisa daging tempatnya melekat. Setelah perendaman operkulum dibilas dalam air mengalir dan dikering anginkan. Operkulum diletakkan diantara dua gelas benda dan ditindih dengan pemberat (sekitar $0,5-1 \mathrm{~kg}$ ) selama minimal dua hari, agar operkulum tidak melengkung. Penindihan dilakukan pada saat operkulum masih basah agar tidak pecah. Sebagai catatan, tidak semua operkulum bisa diperlakukan seperti ini, ada jenis-jenis yang memang aslinya melengkung, sehingga proses penindihan bisa diabaikan.

Operkulum kering diamati lapisan pertumbuhannya dengan menggunakan mikroskop stereoskopis. Operkulum yang cukup tipis dan transparan diamati dengan mudah lapisan adventisiusnya dengan pencahayaan belakang (Ramon et al., 1995).

Operkulum yang tidak jernih di tanam dalam Canada balsam dan dipotong menurut aksis terpanjangnya dan melewati inti operkulum (Gambar 1) menggunakan minidrill (gergaji putar mini) bertabur serbuk berlian. Permukaan potongan dibasahi kemudian diampelas 
menggunakan amplas halus dengan hati-hati, dicuci dengan air tawar dan dikeringanginkan selama 24 jam. Kemudian ditanam dalam gelas benda dan penutupnya, dihitung jumlah lapisan operkulumnya di bawah mikroskop (Richardson et al., 2005a).

Mikroskop yang dipergunakan pada metode 1, pengamatan langsung operkulum yang tipis, dan metode 2, dengan penanaman dalam resin, adalah Olympus CX24, yang dihubungkan dengan OptiLab viewer dan kamera digital Olympus Camedia C-7070 wide zoom 7,1 megapixel, dengan pencahayaan yang kuat dapat diambil citra digitalnya secara langsung. Metode kedua merupakan kelanjutan dari metode pertama, maka hasil dari kedua metode ini tidak diperbandingkan, sebab tujuan utamanya adalah untuk menghitung jumlah lapisan adventisius operkulum.

Panjang cangkang yang didapatkan dipergunakan untuk menghitung nilai $K$, kurvatur kecepatan pertumbuhan Von Bertalanffy Growth Formula (VBGF). Adapun persamaan von Bertalanffy adalah sebagai berikut: $\mathrm{L}_{\mathrm{t}}=\mathrm{L}_{\infty}\left(1-\exp ^{-\mathrm{K}(\mathrm{t}-\mathrm{to})}\right)$ dengan $\mathrm{L}_{\mathrm{t}}$ : panjang pada saat $t, \mathrm{~L}_{\infty}$ : panjang rata-rata siput yang amat tua, to adalah parameter kondisi awal (Sparre dan Venema, 1999). Nilai ini didapatkan dengan menggunakan data frekuensi panjang yang disusun berdasarkan waktu dan diproses menggunakan software FiSAT yang didownload dari website FAO. $\mathrm{K}$ dan $\mathrm{L}_{\infty}$ diestimasi dengan analisis Elefan I yang terdapat pada FiSAT (Gayanilo et al., 2005), dan to didapatkan dengan persamaan von Bertallanffy terbalik: $t(L)=t o-(1 / K) * \ln \left(1-\left(L / L_{\infty}\right) \quad(\right.$ Sparre dan Venema, 1999).

Analisis regresi dilakukan pada panjang operkulum dan panjang cangkang, serta jumlah lapisan adventisius operkulum dan panjang cangkang.

\section{Hasil dan Pembahasan}

Hasil pemrosesan operkulum menggunakan metode 1 (Gambar 2A) dan metode 2 yang ditanam dalam Canada Balsam (Gambar 2B). Sisi permukaan yang paucispiral terlihat sebagai satu lapisan saja pada bagian atas, dan lapisan selanjutnya adalah lapisan yang konsentris.

Sejumlah 101 dari 165 sampel berhasil dianalisis dalam tes hubungan panjang cangkang dengan panjang operkulum Rhinoclavis sinensis. Hasil analisis menunjukkan bahwa panjang cangkang dan panjang operkulum memiliki hubungan yang positif, dengan persamaan garis regresi $Y=0,113 X+1,898\left(R^{2}=0,857\right)$. Hasil ini mengindikasikan bahwa pertumbuhan panjang cangkang diikuti dengan pertumbuhan panjang operkulum. Oleh karena itu panjang operkulum dapat diprediksi dari panjang cangkang dan sebaliknya. Hasil ini juga menunjukkan bahwa ada perbedaan kecepatan pertumbuhan, yaitu setiap pertambahan panjang cangkang $1 \mathrm{~mm}$ diikuti dengan pertambahan panjang operkulum sebesar $0,113 \mathrm{~mm}$.

Sejumlah 64 sampel berhasil dianalisis untuk tes hubungan panjang cangkang dengan jumlah lapisan operkulum. Tes ini menunjukkan adanya hubungan positif antara panjang cangkang dan jumlah lapisan operkulum ( $\mathrm{Y}=$ $0,167 X ; R^{2}=0,872$ ).

Saat awal kelahiran, pertumbuhan akan cepat, tetapi pertumbuhan akan melambat saat umur mencapai kedewasaan dan saat penuaan. Populasi yang dipanen secara berkesinambungan di bawah ambang batas akan merespons dengan mempercepat pertumbuhannya.

Dengan mengambil kisaran panjang cangkang yang ada pada Tabel 1, Gambar 3 dibuat untuk menyatukan semua variabel yang dipelajari seperti regresi antara jumlah lapisan operkulum dan panjang cangkang, serta nilai $\mathrm{K}$, dalam satu grafik, yaitu dengan memasukkan panjang cangkang dari umur yang diinginkan. Gambar 3 ini kemudian digunakan untuk kalibrasi penentuan umur spesimen yang didapatkan dari lapangan. Dengan cara yang sama regresi antara panjang operkulum dan panjang cangkang siput juga bisa digunakan untuk kalibrasi.

Gambar 3, memperlihatkan bahwa dibawah umur dua tahun, tiap enam bulan terbentuk selembar lapisan adventisius. Pada umur dua, tiga dan empat tahun pertambahan menjadi selapis pertahun, kemudian pada umur lima dan enam, pertumbuhan sudah sangat melambat, sehingga pada umur tujuh tahun mencapai tujuh lapisan operkulum (Tabel 1). 
Dibawah umur dua tahun, pertumbuhan berfokus pada pertumbuhan somatis, yaitu pertumbuhan panjang dan besar tubuh bertambah dengan cepat. Kecepatan pertumbuhan yang pesat penting untuk menghindari predasi. Umur dua dan tiga tahun adalah dimulainya masa perkembangan organ-organ reproduksi, yaitu saat siput mulai belajar menghasilkan gamet hingga mencapai kedewasaan pada ukuran panjang cangkang $28 \mathrm{~mm}$. Pada ukuran ini $50 \%$ individu telah mampu menghasilkan gamet.
Puncak masa reproduksi diduga pada umur empat tahun, yaitu saat pertumbuhan somatis siput hampir berhenti tetapi kapasitas reproduksinya justru meningkat. Umur lima, enam dan tujuh tahun mungkin masih bereproduksi tetapi diperkirakan sudah mulai menurun. Lebih-lebih jumlah anggota populasi yang mencapai ukuran $\pm 38 \mathrm{~mm}$ ke atas sudah amat sedikit sehingga perannya dalam populasi mulai berkurang.

Tabel 1. Panjang cangkang $R$. sinensis pada nilai kurvatur dan umur yang berbeda.

\begin{tabular}{cccccccccc}
\hline \hline & \multicolumn{10}{c}{ Umur } & $\mathbf{7}$ & $\mathbf{6}$ & $\mathbf{7}$ \\
\hline Tahun; K & $\mathbf{0 , 5}$ & $\mathbf{1}$ & $\mathbf{1 , 5}$ & $\mathbf{2}$ & $\mathbf{3}$ & $\mathbf{4}$ & $\mathbf{5}$ & 41,2 & 42,1 \\
\hline $\mathbf{2 0 0 8 ;} \mathbf{0 , 4 9}$ & 8,0 & 15,8 & 21,8 & 26,5 & 33,1 & 37,2 & 39,7 & 41,2 \\
\hline \hline
\end{tabular}

Keterangan: K: kurvatur VBGF

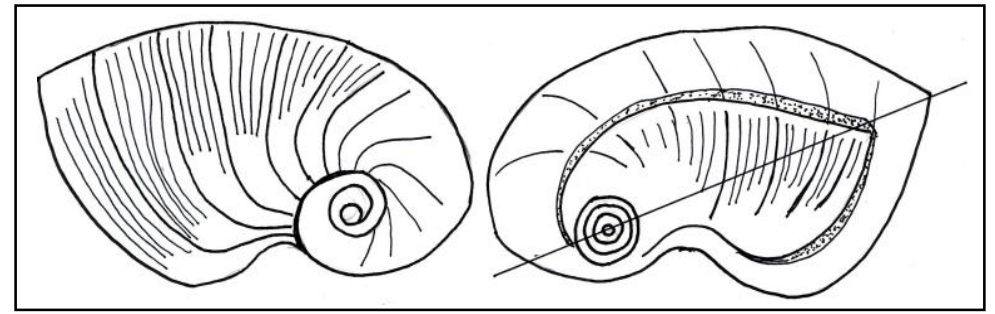

Gambar 1. Arah pemotongan pada aksis terpanjang operkulum dengan memperhitungkan melewati inti serta semua lapisan yang terbentuk. Kiri, sisi permukaan dan kanan, sisi perlekatan. Gambar oleh Zahida, perbesaran 40 kali.

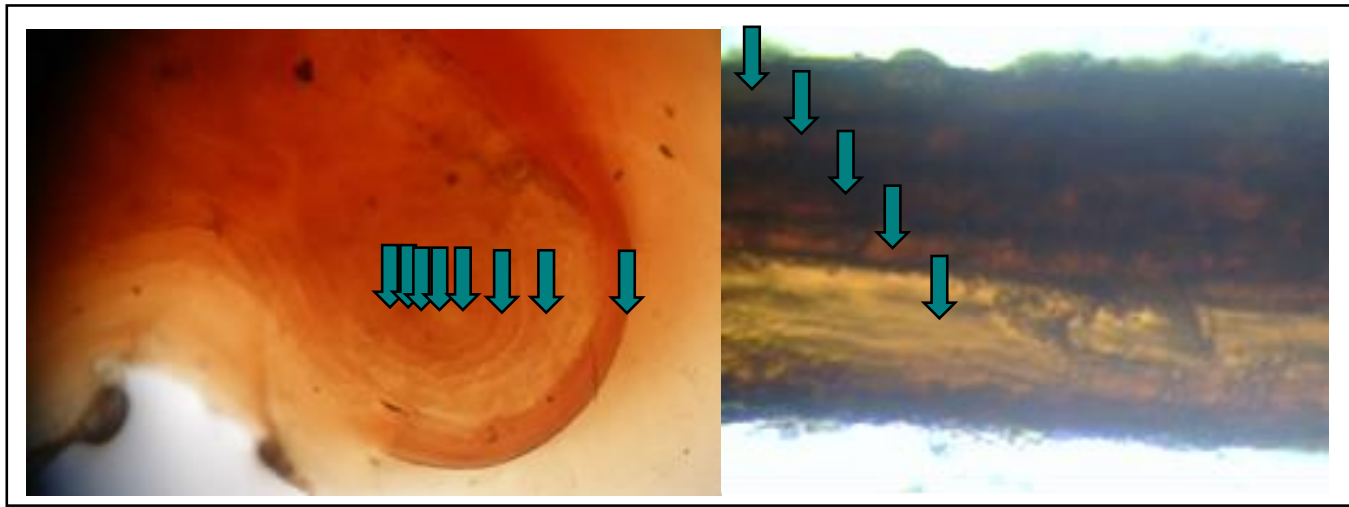

Gambar 2. A. Operkulum dengan tujuh lapisan adventisius. Tanda panah paling kiri inti operkulum. Inti terbentuk saat perkembangan dalam telur, sehingga umur mulai dihitung pada lapis kedua yang muncul saat lahir. B. Lapisan-lapisan operkulum, sisi paucispiral berwarna coklat tua sedangkan warna coklat muda menunjukkan bagian yang baru terbentuk. Foto oleh Zahida, perbesaran 40 kali. 


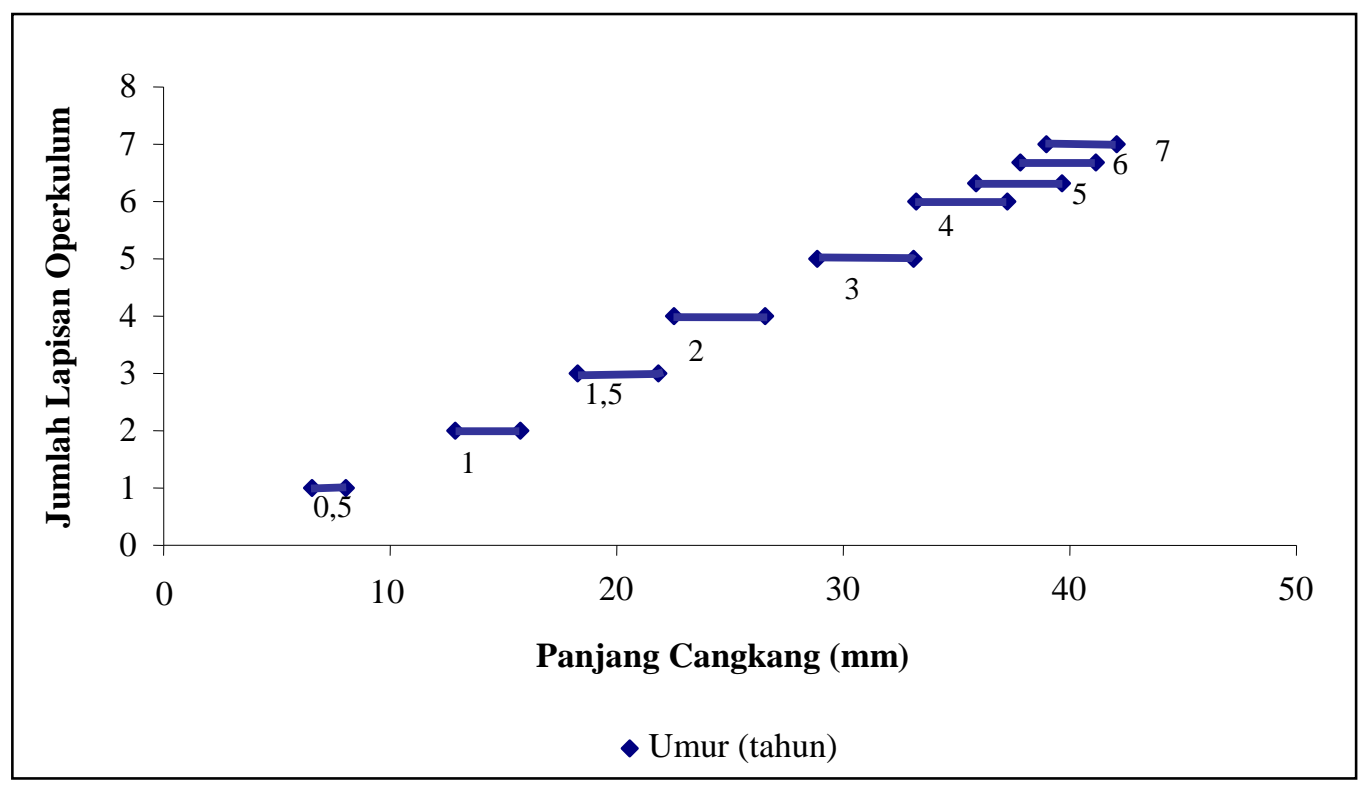

Gambar 3. Jumlah lapisan operkulum, panjang cangkang dan umur $R$. sinensis.

\section{Simpulan}

Hasil penelitian ini menambah bukti empiris bahwa panjang dan jumlah lapisan adventisius operkulum dapat digunakan sebagai penentu umur $R$. sinensis. Selain itu diperoleh hasil bahwa penambahan panjang $1 \mathrm{~mm}$ cangkang terjadi penambahan panjang $0,113 \mathrm{~mm}$ operkulum. Seiring dengan kecepatan pertumbuhannya (nilai kurvatur, K), didapatkan bahwa kecepatan pertumbuhan lapisan adventisius operkulum dua tahun pertama sangat cepat (dua lapisan adventisius pertahun). Pada umur tiga dan empat tahun pertambahan menjadi selapis per tahun, kemudian pada umur lima dan enam, pertumbuhan sudah amat melambat, sehingga pada umur tujuh tahun mencapai tujuh lapisan operkulum.

\section{Ucapan Terima Kasih}

Ucapan terima kasih, disampaikan pada Bapak George Hadiprayitno dan Bapak Bunjamin Dharma dari Solaris Shell Club yang telah melakukan verifikasi mengenai jenis Rhinoclavis sinensis ini, mengingat begitu beragamnya jenis yang berkerabat dengannya.
Terima kasih kepada Lestari Novalida Sitepu dan Nawang Widyhasworo, sebagai teknisi di lapangan dan di laboratorium. Penelitian ini didanai oleh program beasiswa Pasca Sarjana, BPPS 2005-2008 dan Universitas Atma Jaya Yogyakarta 2008-2010.

\section{Daftar Pustaka}

Aldridge, D.C. 1999. The Morphology, Growth and Reproduction of Unionidae (Bivalvia) in a Fenland Waterway. J. Molluscan Studies, 65: 47-60.

Gaspar, M.B., Pereira, A.M., Vasconcelos, P. dan Monteiro, C.C. 2004. Age and Growth of Chamelea gallina from Algarve Coast (Southern Portugal): Influence of Seawater Temperatur and Gametogenic Cycle on Growth Rate. J. Molluscan Studies, 70 (4): 371-377.

Gayanilo, F.C.Jr., Sparre, P. dan Pauly, D. 2005. FAOICLARM Stock Assessment Tools II (FiSAT II). Revised version. User's Guide. FAO Computerized Information Series (Fisheries). No. 8, Revsed version. Rome, FAO.2005.168 p.

Houbrick, R.S. 1978. The Family Cerithiidae in the IndoPacific. Part 1: The Genera Rhinoclavis, Pseudovertagus and Clavocerithium. In: Abbott, R.T. (Eds.). Monographs of Marine Mollusca. No.1. American Malacologists, Inc.Delaware. Pp: 130. 
Kideys, A.E. 1996. Determination of Age and Growth of Buccinum undatum L. (Gastropoda, Prosobranchia) off Douglas, Isle of Man. Helgol. Meeresunters, 50: 353-368.

Monfils, P. 2000. The Old Shell Game. American Conchologist, 28 (4): 22-26.

Ramon, M., Abello, P. dan Richardson, C.A. 1995. Population Structure and Growth of Donax trunculus (Bivalvia: Donacidae) in the Western Mediterranean. Marine Biology, 122: 65-671.

Richardson, C.A., Saurel, C., Barroso, C.M. dan Thain, J. 2005a. Evaluation of the Age of the Red Whelk Neptunea antiqua using Statoliths, Opercula and Element Ratios in the Shell. $J$. Experimental Marine Biology and Ecology, 325: 55-64.
Richardson, C.A., Kingsley-Smith, P.R., Seed, R. dan Chatzinikolaou, E. 2005b. Age and Growth of Naticid Gastropod Polinices pulcellus (Gastropoda: Naticidae) Based on Length Frequency Analysis and Statolith Growth Rings. Marine Biology, 148: 319-326.

Sparre, P. dan Venema, S.C. 1999. Introduksi Pengkajian Stok Ikan Tropis. Buku 1: Manual. Pusat Penelitian dan Pengembangan Perikanan, Jakarta. 438hal. 